\title{
A propósito de un caso de Fiebre de Chikungunya importada de América
}

\author{
Membrillo de Novales FJ. ${ }^{1}$, Fe Marqués A. ${ }^{2}$, Pilares Barco JM. ${ }^{3}$, Mateo Maestre M. ${ }^{4}$, Pérez Mochales JF. ${ }^{5}$ \\ Sanid. mil. 2015; 71 (3): 183-185; ISSN: 1887-8571
}

\begin{abstract}
RESUMEN
Presentamos el caso de un varón de 41 años que tras viajar como VFR (Visiting Friends and Relatives) a Valencia, Venezuela, presentó a su regreso a España un cuadro de fiebre y artromialgias. El paciente cumplía criterios clínicos para el diagnosticado de fiebre de Chikungunya, recientemente introducida en América y donde se desarrolla en la actualidad una epidemia que afecta al país que viajó. El estudio serológico por el laboratorio de referencia confirmó esta sospecha al detectar IgM frente a virus Chikungunya (CHIKV). Al tratarse de una arbovirosis poco conocida en nuestro medio y de interés militar, aprovechamos el caso, primero diagnosticado en nuestro Hospital en el contexto de esta epidemia, para revisar la situación de esta enfermedad y la epidemiología del brote actual.
\end{abstract}

PALABRAS CLAVE: Chikungunya, Arbovirosis, Aedes spp, Medicina Tropical.

\section{Regarding a case of Chikungunya fever imported from America}

SUMMARY: We present a case of a 41-year-old male who travelled to Valencia, Venezuela as a VFR (Visiting Friends and Relatives) and presented fever and arthromyalgias upon his return to Spain. The patient met clinical criteria for the diagnosis of Chikungunya fever, recently introduced in the American continent, where a developing outbreak affects the country he travelled to. Serological testing in the reference laboratory confirmed this suspicion, detecting IgM against Chikungunya virus (CHIKV). Given that this arbovirosis is not well known in our environment and it is of military interest, we use this case, the first one diagnosed in our Hospital in the context of this epidemic, to review the situation of this disease and the epidemiology of the outbreak.

KEYWORDS: Chikungunya, Arbovirosis, Aedes spp, Tropical Medicine.

\section{INTRODUCCIÓN}

La fiebre de Chikungunya o enfermedad por virus Chikungunya (CHIKV) es una arbovirosis producida por un virus del género Alphavirus, familia Togaviridae ${ }^{1}$. Su principal vector de transmisión es el mosquito Aedes aegypti, aunque puede actuar también como vector menos efectivo el mosquito Aedes albopic$t u s^{2}$. El periodo de incubación tras la picadura oscila entre uno y siete días. El cuadro clínico tiene un inicio súbito consistente en fiebre, escalofríos, cefalalgia, anorexia, conjuntivitis y artralgias que pueden llegar a ser incapacitantes. En ocasiones aparece posteriormente un rash maculo-papular. El nombre de la enfermedad significa "andar doblado" en el idioma Kimakondé de la tribu Makonde, que vive en un territorio que se extiende entre el sudeste de Tanzania y el norte de Mozambique donde se detectó por primera vez el virus ${ }^{3}$. La enfermedad se resuelve de forma espontánea en 7-10 días, aunque las artralgias pueden persistir durante semanas o meses.

\footnotetext{
${ }^{1}$ Cap. Médico. Unidad NRBQ-Infecciosas.

${ }^{2}$ Cor. Médico. Unidad NRBQ-Infecciosas.

${ }^{3}$ Médico Civil. Servicio de Urgencias.

${ }^{4}$ Cte. Médico. Servicio de Microbiología.

${ }_{5}^{5}$ Cor. Médico. Servicio de Medicina Interna, Hospital Central de la Defensa. Madrid. España
}

Dirección para correspondencia: Francisco Javier Membrillo de Novales. Unidad de Alertas NRBQ y Enfermedades Infecciosas, Hospital Central de la Defensa. Glorieta del Ejército, 1. Madrid 28047. Tlfno 636099026. E-mail: javimembrillo@gmail.com

Recibido: 21 de noviembre de 2014

Aceptado: 30 de marzo de 2015
Se considera caso sospechoso de CHIKV todo paciente con fiebre mayor de $38,5^{\circ} \mathrm{C}$ y artralgia grave que no pueda ser explicada por otra etiología y que reside o ha visitado áreas epidémicas o endémicas durante las dos semanas anteriores al inicio de los síntomas. Los criterios epidemiológicos, como expondremos posteriormente, no siempre se cumplen dada la distribución fuera de zonas endémicas de los vectores de transmisión. El diagnóstico de confirmación se realiza por al menos una técnica microbiológica que ponga de manifiesto la infección ${ }^{4}$. La técnica más utilizada es la detección de $\operatorname{IgM}$ sérica, que se eleva a partir del cuarto o quinto día desde el comienzo de los síntomas. Otras alternativas de diagnóstico microbiológico son la detección de ácido nucleico viral mediante PCR y el aislamiento del virus mediante cultivo en sangre, líquido cefalorraquídeo o tejidos ${ }^{5}$. No existen antivirales efectivos ni vacuna. El tratamiento se limita a medidas de soporte o control de los síntomas con antiinflamatorios y analgésicos. Los casos de fallecimiento son excepcionales y en el contexto de comorbilidades.

El CHIKV es considerado una enfermedad tropical, aunque esporádicamente se presentan casos en viajeros, especialmente en caso de epidemias ${ }^{6,7}$ y personal militar, lo que determina su especial importancia para la sanidad militar española, dado que es endémica en regiones geográficas donde nuestras tropas están desplegadas en la actualidad ${ }^{8}$. Es enfermedad de declaración epidemiológica ${ }^{4}$, y su vigilancia es de especial importancia dado que Aedes albopictus habita actualmente en España. En 2004 se detectó por primera vez en Sant Cugat del Vallés, Barcelona, y desde entonces se ha extendido por el levante desde Gerona hasta Murcia, creando un potencial riesgo de establecer un reservo- 
rio de CHIKV a través de pacientes importados que podría dar lugar teóricamente a la introducción de la enfermedad en territorio nacional ${ }^{9,10}$. De hecho, en una situación similar, en 2007 se produjo un brote de CHIKV en Italia, que se controló con medidas dirigidas a la erradicación del vector ${ }^{11}$. En el momento actual hay un brote en curso en Francia, con hasta cuatro casos en una misma familia por contacto con un enfermo procedente de Camerún ${ }^{12}$.

En América central y Sudamérica, donde los mosquitos del género Aedes están ampliamente distribuidos y hace décadas que se hizo endémico el dengue, con igual vector y mecanismo de transmisión, se temía desde hace años la introducción del $\mathrm{CHIKV}^{13}$. En efecto, en diciembre de 2013 la OMS informó del primer caso de transmisión local de CHIKV en el continente americano en la isla de San Martin ${ }^{14,15}$. Desde entonces la enfermedad se ha distribuido en magnitud de epidemia por prácticamente todo el Caribe y Centroamérica, Estados Unidos y varios países de Sudamérica (Guyana, Guayana Francesa, Surinam, Brasil, Colombia, Venezuela y Paraguay), superando los cien mil casos sospechosos en los cinco primeros meses de $2014^{16} \mathrm{y}$ con informes preliminares que informan de más de un millón de casos sospechosos declarados hasta el 12 de diciembre de 2014, aunque de éstos solo 20.209 corresponden a casos confirma$\operatorname{dos}^{17}$. Simultáneamente, en múltiples países americanos y europeos se han comenzado a detectar casos importados de CHIKV procedente de América. Presentamos el primer caso de CHIKV proveniente de América diagnosticado en el Hospital Central de la Defensa "Gómez Ulla".

\section{OBSERVACIÓN CLÍNICA}

Varón de 41 años, sin reacciones adversas a medicamentos conocidas, bebedor ocasional, sin otros antecedentes de interés. El paciente no tomaba medicación de forma habitual. Natural de Venezuela, vive en Madrid desde 2007. Nunca ha viajado a otros países. Cartilla de vacunación actualizada, incluyendo fiebre amarilla y hepatitis $\mathrm{B}$.

En septiembre de 2014 el paciente viajó a Venezuela para visitar a sus familiares. Durante su estancia vive en la ciudad de Valencia. En los alrededores del domicilio familiar observó abundantes zonas de agua estancada e insectos. A lo largo de su visita varios familiares que convivían con él y vecinos sufrieron cuadros febriles siendo diagnosticados de enfermedad por virus Chikungunya. Sufrió múltiples picaduras de insectos. No refiere clínica significativa ni otros riesgos epidemiológicos durante su estancia en Venezuela.

Regresó a Madrid en octubre de 2014 tras un mes de estancia en Venezuela. Desde su llegada comenzó con un cuadro de sensación distérmica no termometrada, escalofríos y tiritona, asociada a debilidad generalizada, artromialgias y astenia intensa. Se automedicó con Ibuprofeno $600 \mathrm{mg}$ vía oral cada 8 horas sin mejoría, por lo que al segundo día de iniciada la clínica acudió a Urgencias.

En su exploración física destacaba una temperatura timpánica de $38,3^{\circ} \mathrm{C}$, frecuencia cardíaca de 100 latidos por minuto, no se detectan otros hallazgos. En los análisis de urgencias destacaron GOT de 33 U/1, GPT de $47 \mathrm{U} / 1$, proteína C reactiva de 2,13 $\mathrm{mg} / \mathrm{dl}$, y un recuento de linfocitos en el rango bajo de la normalidad (650 linfocitos por $\mu 1)$. El resto de los estudios complementarios fueron normales. Se tomaron muestras para hemocultivo y urocultivo, y ante la estabilidad clínica y con sospecha diagnóstica de enfermedad por virus Chikungunya se decidió dar de alta a domicilio y continuar el estudio de forma ambulatoria en la consulta de Enfermedades Infecciosas con la realización, al día siguiente, de un estudio serológico.

El paciente no acudió a la extracción de sangre hasta 6 días después. Refería mejoría paulatina. La fiebre duró 3 días y los dolores articulares generalizados disminuyeron de forma clara al ceder la fiebre, aunque persistieron molestias, junto con astenia. Se tomaron muestras para serología de virus de hepatitis A, B, C, VIH y sífilis como primera aproximación para un diagnóstico diferencial (dentro del estudio habitual solicitado para estudio de fiebre importada) y se envió una muestra para diagnóstico serológico al centro de referencia (Centro Nacional de Microbiología Carlos III-Majadahonda) para CHIKV y dengue. El hallazgo de IgM positiva con IgG negativa frente a CHIKV, mediante Inmunofluorescencia Indirecta (IFI), junto con la serología negativa a dengue, confirmó el diagnóstico de sospecha de infección reciente. El resto de resultados serológicos fueron negativos salvo patrón de inmunidad al virus de la hepatitis $B$.

El paciente se encontraba asintomático a los 10 días del inicio del cuadro. Un mes más tarde se envió una nueva muestra de seguimiento al Centro Nacional de Microbiología, que reveló la seroconversión de IgG frente a CHIKV mediante IFI.

\section{DISCUSIÓN}

Decenas de millones de personas realizan viajes internacionales cada año, cifra en aumento por diversos motivos (migraciones, turismo, viajes de negocios y misiones internacionales en el caso de las Fuerzas Armadas y Fuerzas y Cuerpos de Seguridad del Estado). Entre el 20 y el 70\% de los viajeros de países industrializados, según series, refieren algún síntoma al regreso de viajes a países en vías de desarrollo. Las enfermedades infecciosas constituyen una causa baja de mortalidad pero la primera causa de morbilidad de los viajeros internacionales. La fiebre es un marcador de potencial gravedad en estos pacientes, por lo que su presencia al regreso del viajero es un problema diagnóstico de extrema importancia. Estas enfermedades constituyen un reto para los sistemas sanitarios y generalmente requieren el apoyo de personal especializado en Medicina Tropical y enfermedades emergentes. Estos especialistas deben realizar un esfuerzo continuo de actualización en la situación epidemiológica mundial. Su existencia probablemente aporta un beneficio para la capacidad de respuesta dada la experiencia que consiguen al agrupar el reducido número de casos de patologías no endémicas en nuestro medio.

Dentro del viajero internacional se define como un subgrupo especial el de los VFR (Visiting Friends and Relatives). Se definen como viajeros de etnia distinta a la del país de origen pero similar a la del país de destino, cuyo propósito de viaje es visitar a amigos o familiares, en lugares con riesgo de contraer enfermedades infecciosas tropicales ${ }^{18}$. Se propone la definición de dos subgrupos, VFR inmigrantes y VFR viajeros, para incluir en este 


\section{A propósito de un caso de Fiebre de Chikungunya importada de América}

último a los hijos o cónyuges de los VFR que viajan con ellos, y por tanto están expuestos a los mismos riesgos epidemiológicos. En los VFR, el riesgo de contraer enfermedades durante el viaje es mayor, dado que generalmente conviven más íntimamente con los riesgos autóctonos de la región de destino, y en muchos casos no se protegen frente a dichos riesgos con igual empeño que los demás viajeros, al considerarse protegidos por su etnicidad de enfermedades que erróneamente la población identifica como graves solo para extranjeros.

En el caso que nos ocupa, nuestro paciente viajó en efecto como VFR inmigrante, sin protegerse adecuadamente frente a las picaduras de insectos a pesar de encontrarse en una zona de riesgo en el contexto de una epidemia de una enfermedad emergente y aun conociendo el mecanismo de transmisión de la misma. Posiblemente, un adecuado consejo previo al viaje impartido por una unidad especializada de Medicina Tropical podría haber evitado el contagio del CHIKV, enfermedad que generalmente cursa de forma benigna pero incapacita para la actividad diaria y laboral durante un plazo que puede llegar a ser de varios meses.

Por otra parte, consideramos de interés llamar la atención sobre tres aspectos de importancia para la Sanidad Militar española a propósito de este caso. En primer lugar, la facilidad con la que un médico sin actualización continuada en epidemiología de las enfermedades emergentes puede confundir una fiebre de Chikungunya importada con un cuadro febril gripal o vírico de otra etiología. Nuestras tropas se encuentran desplegadas en regiones donde la enfermedad por CHIKV es endémica y el médico militar español debe estar preparado para diagnosticar y tratar la patología que nos ocupa. En segundo lugar, la importancia de un significativo número de militares españoles nacidos en países hispanoamericanos que viajan como VFRs en sus permisos a sus países de origen, y podrían por tanto contagiarse de CHIKV y manifestarlo a su regreso a Territorio Nacional estando ya en servicio activo en sus destinos. Y en último lugar, como hemos expuesto, España corre un peligro potencial de sufrir una epidemia de CHIKV autóctono transmitido por Aedes albopictus. Epidemia frente a la que, aunque no tenga la relevancia mediática de otras enfermedades emergentes, debemos estar preparados para responder adecuadamente a la confianza que deposita la sociedad española en la preparación de la Sanidad Militar para hacer frente a amenazas biológicas sobre nuestro territorio nacional. La Sanidad Militar, en conclusión, debe estar preparada para atender las patologías en el campo de las Enfermedades Infecciosas, y dentro de las mismas especialmente las Enfermedades Tropicales y Emergentes.

\section{BIBLIOGRAFÍA}

1. Strauss JH, Strauss EG. The alphaviruses: gene expression, replication, and evolution. Microbiol Rev. 1994 Sep; 58(3):491-562.

2. Meltzer E. Arboviruses and Viral Hemorrhagic Fevers (VHF). Infect Dis Clin N Am 26 (2012) 479-496.

3. Pialoux G, Gaüzère BA, Jauréguiberry S, Strobel M. Chikungunya, an epidemic arbovirosis. Lancet Infect Dis 2007; 7: 319-327.

4. Potocolo de vigilancia de la enfermedad por virus Chikungunya (CHIKV). En: Red Nacional de Vigilancia Epidemiológica. Protocolos de las enfermedades de declaración obligatoria. Disponible en: http://www.isciii.es/ISCIII/ es/contenidos/fd-servicios cientifico-tecnicos/ fd-vigilancias-alertas/ PROTOCOLOS_RENAVE.pdf

5. Negredo A, de Ory F, Sánchez-Seco MP, Franco L, Gegúndez MI, Navarro JM, Tenorio A. Diagnóstico microbiológico de arbovirosis y robovirosis emergentes. Enferm Infecc Microbiol Clin. 2013. Disponible en: http:// dx.doi.org/10.1016/j.eimc.2013.07.011

6. Taubitz W, Cramer J, Kapaun A, Pfeffer M, Drosten C, Dobler G, Burchard G, Löscher T Chikungunya Fever in Travelers: Clinical Presentation and Course. Clinical Infectious Diseases 2007; 45:e1-4.

7. Simon F. et al. Chikungunya infection: an emerging rheumatism among travelers returned from Indian Ocean islands. Report of 47 cases. Medicine (Baltimore). 2007 May; 86(3):123-137.

8. Plaza JF, Navarro R. Arbovirosis y operación ATALANTA: riesgo para viajeros y medidas de prevención y control. Sanid. mil. 2014; 70 (2): 103-113; ISSN: $1887-8571$.

9. Gimenez $\mathrm{N}$ et al. Llegada de Aedes albopictus a España, un nuevo reto para la salud pública. Gac Sanit. 2007;21(1):25-28.

10. Bueno R, Jiménez R. Implicaciones sanitarias del establecimiento y expansión en España del mosquito Aedes albopictus. Rev Esp Salud Pública 2012; 86: 319-330.

11. Charrel RN, de Lamballerie X. Chikungunya virus in north-eastern Italy: a consequence of seasonal synchronicity. Euro Surveill 2008; 13: 8003.

12. WHO Global alert and response. Chikungunya - France. Disponible en: http://www.who.int/csr/don/23-october-2014-chikungunya/en/

13. Organización Panamericana de la Salud. Preparación y respuesta ante la eventual introducción del virus chikungunya en las Américas. Washington, D.C.: OPS, 2011. ISBN: 978-92-75-31632-0

14. CDC. Chikungunya virus. Atlanta, GA: US Department of Health and Human Services; 2014. Disponible en: http://www.cdc.gov/chikungunya.

15. Leparc-Goff I, Nougairede A, Cassadou S, Prat C, Lamballerie X. Chikungunya in the Americas. Lancet 2014; 383: 514.

16. Fischer M, Staples E. Chikungunya Virus Spreads in the Americas - Caribbean and South America, 2013-2014. MMWR Morb Mortal Wkly Rep 2014; 63(22): 500-501

17. WHO/PAHO. Number of Reported Cases of Chikungunya Fever in the Americas, by Country or Territory 2013-2014 (to week noted) Epidemiological Week / EW 45 (Updated 12 December 2014). Disponible en: http://www. paho.org/hq/index.php?option=com_docman\&task=doc_download\&Itemi $\mathrm{d}=$ \&gid=28627\&lang=en

18. Matteelli A, Carvalho AC, Bigoni S. Visiting Relatives and Friends (VFR), Pregnant, and Other Vulnerable Travelers. Infect Dis Clin N Am 26 (2012) 625-635. 